\title{
Dual regulation of voltage-sensitive ion channels by $\mathrm{PIP}_{2}$
}

\author{
Aldo A. Rodríguez-Menchaca ${ }^{\dagger}$, Scott K. Adney, Lei Zhou and Diomedes E. Logothetis*
}

Department of Physiology and Biophysics, School of Medicine, Virginia Commonwealth University, Richmond, VA, USA

Edited by:

Gildas Loussouarn, University of

Nantes, France

Reviewed by:

Mark S. Shapiro, The University of Texas Health Science Center at San Antonio, USA

Show-Ling Shyng, Oregon Health and Science University, USA

\section{${ }^{*}$ Correspondence:}

Diomedes E. Logothetis, Department of Physiology and Biophysics, School of Medicine, Virginia Commonwealth University, Richmond, VA 23298, USA. e-mail:delogothetis@vcu.edu

${ }^{\dagger}$ Present address:

Aldo A. Rodríguez-Menchaca, Departamento de Fisiología y Biofísica, Facultad de Medicina, Universidad Autónoma de San Luis Potosí, San Luis Potosí 78210, México.
Over the past 16 years, there has been an impressive number of ion channels shown to be sensitive to the major phosphoinositide in the plasma membrane, phosphatidylinositol 4,5bisphosphate $\left(\mathrm{PIP}_{2}\right)$. Among them are voltage-gated channels, which are crucial for both neuronal and cardiac excitability. Voltage-gated calcium (Cav) channels were shown to be regulated bidirectionally by $\mathrm{PIP}_{2}$. On one hand, $\mathrm{PIP}_{2}$ stabilized their activity by reducing current rundown but on the other hand it produced a voltage-dependent inhibition by shifting the activation curve to more positive voltages. For voltage-gated potassium (Kv) channels $\mathrm{PIP}_{2}$ was first shown to prevent $\mathrm{N}$-type inactivation regardless of whether the fast inactivation gate was part of the pore-forming $\alpha$ subunit or of an accessory $\beta$ subunit. Careful examination of the effects of $\mathrm{PIP}_{2}$ on the activation mechanism of Kv1.2 has shown a similar bidirectional regulation as in the Cav channels. The two effects could be distinguished kinetically, in terms of their sensitivities to $\mathrm{PIP}_{2}$ and by distinct molecular determinants. The rightward shift of the Kv1.2 voltage dependence implicated basic residues in the S4S5 linker and was consistent with stabilization of the inactive state of the voltage sensor. A third type of a voltage-gated ion channel modulated by $\mathrm{PIP}_{2}$ is the hyperpolarizationactivated cyclic nucleotide-gated $(\mathrm{HCN})$ channel. $\mathrm{PIP}_{2}$ has been shown to enhance the opening of $\mathrm{HCN}$ channels by shifting their voltage-dependent activation toward depolarized potentials. The sea urchin $\mathrm{HCN}$ channel, SplH, showed again a $\mathrm{PIP}_{2}$-mediated bidirectional effect but in reverse order than the depolarization-activated Cav and Kv channels: a voltagedependent potentiation, like the mammalian HCN channels, but also an inhibition of the cGMP-induced current activation. Just like the Kv1.2 channels, distinct molecular determinants underlied the $\mathrm{PIP}_{2}$ dual effects on $\mathrm{SplH}$, with the proximal C-terminus implicated in the inhibitory effect. The dual regulation of these very different ion channels, all of which are voltage-dependent, points to conserved mechanisms of regulation of these channels by $\mathrm{PIP}_{2}$.

\section{Keywords: PIP2, voltage sensor, voltage-gated channels, gating, S4-S5 linker}

\section{INTRODUCTION}

Voltage-gated ion channels regulate the flow of different ions across the membrane in response to changes in membrane potential. These channels are composed of four subunits (or four linked domains) symmetrically arranged around a central ionconducting pore. Voltage-gated ion channels open in response to depolarization or hyperpolarization. The change in membrane potential induces a conformational change in the voltage sensor domain located in the periphery of the ion channel; this conformational change is coupled to the ion-conducting pore, and leads to channel opening (Long et al., 2005; Bezanilla, 2008; Borjesson and Elinder, 2008).

Voltage-gated ion channels can be modulated by numerous factors including free fatty acids (Xiao et al., 2005; Borjesson et al., 2008; Xu et al., 2008a), toxins (Catterall et al., 2007; Swartz, 2007), metal ions (Elinder and Arhem, 2003), glycosylation (Fozzard and Kyle, 2002; Watanabe et al., 2003, 2007), palmitoylation (GubitosiKlug et al., 2005; Jindal et al., 2008), phosphorylation (Davis et al., 2001; Mohapatra and Trimmer, 2006; Mohapatra et al., 2007; Li et al., 2008), and phospholipids (Ramu et al., 2006; Schmidt et al., 2006; Xu et al., 2008b). Modulation by phospholipids includes phosphatidylinositol 4,5-bisphosphate ( $\left.\mathrm{PIP}_{2}\right)$, the lipid component of the inner membrane leaflet that modulates the activity of most ion channels and transporters tested (Suh and Hille, 2005, 2008; Logothetis et al., 2010).

$\mathrm{PIP}_{2}$ plays an important role as an intermediate molecule in multiple receptor signaling pathways. $\mathrm{PIP}_{2}$ hydrolysis by PLC produces 1,4,5-trisphosphate $\left(\mathrm{IP}_{3}\right)$ and diacylglycerol (DAG; Berridge, 1984). $\mathrm{IP}_{3}$ mobilizes $\mathrm{Ca}^{2+}$ from the endoplasmic reticulum, while DAG activates PKC. However, PIP $_{2}$ itself acts as a signaling molecule through direct interactions with target proteins. Our review focuses on the effects of $\mathrm{PIP}_{2}$ on voltage-dependent ion channels, particularly those showing bidirectional regulation.

\section{VOLTAGE-GATED CALCIUM CHANNELS}

Voltage-gated calcium (Cav) channels mediate calcium influx in response to membrane depolarization and regulate intracellular processes such as contraction, secretion, neurotransmission, and gene expression in many different cell types. There are five types of Cav channels: the high voltage-activated L- (Cav1), P/Q- (Cav2.1), $\mathrm{N}-(\mathrm{Cav} 2.2)$, and R- (Cav2.3), and the low voltage-activated T(Cav3; Catterall, 2011). Cav channels are complexes of $\alpha 1, \alpha 2, \beta, \gamma$, 
and $\delta$ subunits. It is in the $\alpha 1$ subunit that the conduction pore and voltage sensor apparatus are located. The $\alpha 1$ subunit is composed of four homologous domains (I-IV), with six transmembrane segments (S1-S6) in each. Similar to Kv and voltage-gated sodium (Nav) channels, the S1-S4 segments serve as the "voltage sensor" and the S5-S6 segments form the "pore domain" (Catterall et al., 2005).

Voltage-gated $\mathrm{Ca}^{2+}$ channels of the Cav2 subfamily (N- and $\mathrm{P} / \mathrm{Q}$-type) are regulated by $\mathrm{G}$ protein coupled receptors via two distinct pathways in sympathetic neurons (Ikeda and Dunlap, 1999). The first is the faster pathway, voltage-dependent, and membrane delimited, induced by direct interaction of the $\mathrm{G}$ protein $\beta \gamma$ subunit with the channel protein (Herlitze et al., 1996; Ikeda, 1996; Dolphin, 2003). The second is the slower pathway that is voltageindependent. It uses signals that stimulate the $\mathrm{G}_{\mathrm{q} / 11}$ type of $\mathrm{G}$ proteins to activate phospholipase C (PLC), which hydrolyzes $\mathrm{PIP}_{2}$ into inositol triphosphate $\left(\mathrm{IP}_{3}\right)$ and diacylglycerol (DAG; Bernheim et al., 1991; Brown et al., 1997). This slower pathway was later attributed to depletion of $\mathrm{PIP}_{2}$ by the activation of PLC (Wu et al., 2002; Gamper et al., 2004). The faster pathway has also been related to $\mathrm{PIP}_{2}$. Rousset et al. (2004) reported that decreasing $\mathrm{PIP}_{2}$ levels suppressed the constitutive inhibition of Cav2.1 channels by endogenous $G \beta \gamma$ subunits. These authors proposed that stabilization of the G $\beta \gamma$ sensitive state of Cav2.1 channels may require direct interaction with $\mathrm{PIP}_{2}$. However, additional studies are needed to firmly establish the importance of $\mathrm{PIP}_{2}$ in this pathway.

The first study on Cav channel modulation by $\mathrm{PIP}_{2}$ reported that this phosphoinositide induces two opposing modulatory effects on Cav2.1 channels (Wu et al., 2002). Rundown of Cav2.1 channels in inside-out patches of Xenopus oocytes was greatly slowed and even reversed by the application of exogenous $\mathrm{PIP}_{2}$ or Mg-ATP to the patch. Conversely, the application of $\mathrm{PIP}_{2}$ antibody accelerated rundown, suggesting that $\mathrm{PIP}_{2}$ stabilizes the activity of Cav2.1 channels and its depletion induces rundown. $\mathrm{PIP}_{2}$ also exerted a voltage-dependent inhibitory effect by shifting the voltage dependence of activation toward depolarized potentials. This effect was antagonized by activation of protein kinase A (PKA; Wu et al., 2002). Modulation of Cav2.1 channels by $\mathrm{PIP}_{2}$ has also been reported to occur in neostriatal projection neurons. Stimulation of muscarinic M1 receptors inhibited Cav2.1 channels in these neurons, an effect that could be abolished by inhibition of PLC. Consistent with these results, intracellular application of $\mathrm{PIP}_{2}$ inhibited all muscarinic modulation of Cav2.1 channels (Perez-Burgos et al., 2010).

In subsequent studies, Cav2.2 modulation by $\mathrm{PIP}_{2}$ was also reported (Gamper et al., 2004). In inside-out Xenopus oocytes patches expressing Cav2.2 channels, PIP $_{2}$ significantly slowed or reversed the rundown of these channels. In native Cav2.2 channels from sympathetic neurons, the current inhibition by muscarinic M1 receptor activation was diminished by intracellular application of diC8-PIP 2 , and the current recovery was abolished when $\mathrm{PIP}_{2}$ synthesis was blocked. Interestingly, activation of bradykinin receptors, which also activate PLC and induce $\mathrm{PIP}_{2}$ hydrolysis, failed to inhibit Cav2.2 currents in the same neurons in which muscarinic $\mathrm{M} 1$ receptor activation was effective, an effect attributed to a probable concurrent $\mathrm{Ca}^{2+}$-mediated stimulation of $\mathrm{PIP}_{2}$ synthesis (Gamper et al., 2004). In a different study with the same type of neurons, bradykinin-induced voltage-independent inhibition of $\mathrm{Ca}^{2+}$ channels was reported and this effect could be abolished by inhibiting PLC, but it was not altered by inhibiting its downstream effectors (Lechner et al., 2005). The discrepancies with the previous study (i.e., Gamper et al., 2004) were attributed by the authors to differences in experimental conditions, such as the use of different cell culture media, differences in the buffering of intracellular $\mathrm{Ca}^{2+}$ concentrations, differences in intracellular $\mathrm{Mg}^{2+}$, and differences in the voltage protocols used.

Another hypothesis for the slow $\mathrm{G}_{\mathrm{q} / 11}$ mediated inhibition of $\mathrm{L}-, \mathrm{N}-$, and $\mathrm{P} / \mathrm{Q}$ calcium channels involves arachidonic acid (AA). $\mathrm{G}_{\mathrm{q} / 11}$ coupled receptor stimulation can acutely activate $\mathrm{PLA}_{2}$ with the subsequent production of $\mathrm{AA}$, which is proposed as the main signal mediating Cav channels inhibition (Roberts-Crowley et al., 2009). Thus, the same receptors that induce $\mathrm{PIP}_{2}$ depletion can cause concurrent release of AA and modulate Cav channels according to the AA hypothesis.

A recent elegant study used two strategies to deplete $\mathrm{PIP}_{2}$ without the production of the PLC downstream products (Suh et al., 2010). PIP $_{2}$ was depleted by rapamycin-induced translocation of an inositol lipid 5-phosphatase and a voltage-sensitive 5-phosphatase (VSP). These systems convert $\mathrm{PI}(4,5) \mathrm{P}_{2}$ to $\mathrm{PI}(4) \mathrm{P}$ in the plasma membrane of intact cells, without activation of $\mathrm{G}$ protein-coupled receptors. Both systems suppressed Cav1.2, Cav1.3, Cav2.1, and Cav2.2 channels. Irreversible depletion of endogenous $\mathrm{PIP}_{2}$ by rapamycin-induced translocation of INP54p 5-phosphatase to the plasma membrane irreversibly inhibited whole-cell Cav currents. On the other hand, reversible depletion of $\mathrm{PIP}_{2}$ by the activation of the zebrafish voltage-sensitive phosphatase Danio rerio (Dr-VSP) reversibly inhibited Cav channels in whole-cell recordings, suggesting that $\mathrm{PIP}_{2}$ is a cofactor required for channel activity. These results with intact cells (whole-cell experiments) did not completely recapitulate the effects reported in inside-out patches with Cav2.1 and Cav2.2 channels (Wu et al., 2002; Gamper et al., 2004). While in excised patches currents ran down almost completely, in intact cells $\mathrm{PIP}_{2}$ depletion inhibited Cav2.1 currents by $29 \%$ and Cav2.2 by $55 \%$. In addition, the inhibitory actions of $\mathrm{PIP}_{2}$ were not observed. These differences as suggested by the authors could potentially reflect preservation in the whole-cell recordings of phosphorylation in some channels or cytoplasmic factors that make channels less $\mathrm{PIP}_{2}$ sensitive or preserving $\mathrm{PIP}_{2}$ synthesis that prevents full $\mathrm{PIP}_{2}$ depletion (Suh et al., 2010).

Recently, it was demonstrated that the $\beta$ subunits of voltagegated $\mathrm{Ca}^{2+}$ channels also influence regulation by $\mathrm{PIP}_{2}$ (Suh et al., 2012). Cav channels co-expressed with the $\beta 3$ subunit could be partially inhibited by activating a voltage-sensitive lipid phosphatase to deplete $\mathrm{PIP}_{2}$ (Suh et al., 2010). However, when these channels were co-expressed with the $\beta 2 \mathrm{a}$ subunit, the inhibition was smaller (Suh et al., 2012). The palmitoylation of two cysteine residues in the $\mathrm{N}$ terminus of the $\beta 2 \mathrm{a}$ subunit was responsible for this decrease in inhibition of Cav channel activity. When the palmitoylation sites were mutated, the $\beta 2$ a subunit behaved more like a $\beta 3$ subunit. Furthermore, addition of a lipidation motif to $\beta 3$ subunits reduced the inhibitory effects of Cav channels, similar to the palmitoylated $\beta 2$ a subunit (Suh et al., 2012). Thus, Cav channel 
regulation by $\mathrm{PIP}_{2}$ is dependent on both the $\alpha$ and $\beta$ subunits. Previously, a similar pattern of $\beta$ subunit effects on arachidonic acid modulation of Cav channels was reported (Heneghan et al., 2009; Mitra-Ganguli et al., 2009).

\section{VOLTAGE-GATED POTASSIUM CHANNELS}

Voltage-gated potassium $(\mathrm{Kv})$ channels are involved in diverse physiological processes, including action potential repolarization, secretion of hormones and neurotransmitters, contraction of skeletal muscle, and others. Kv channels are homotetrameric, with each subunit containing the S1-S4 voltage sensor domain and the S5-S6 central pore domain (Yellen, 2002). As with Cav channels, the movement of the voltage sensor domain in response to membrane depolarization initiates conformational changes that lead to the pore opening. After channel opening, Kv channels undergo a time-dependent loss of conductivity by a mechanism termed inactivation. Two distinct mechanisms of inactivation have been described, N-type (or "ball and chain") inactivation, in which the $\mathrm{N}$-terminal domain of certain $\alpha$ or $\beta$ subunits of $\mathrm{Kv}$ channels plugs the open channel pore from the cytoplasmic side (Hoshi et al., 1991), and C-type inactivation, which appears to result from constriction of the selectivity filter (Yellen, 1998).

Only a few studies have demonstrated $\mathrm{PIP}_{2}$ involvement in the regulation of voltage-dependent $\mathrm{K}^{+}$channels. $\mathrm{PIP}_{2}$ shows remarkable effects on the $\mathrm{N}$-type inactivation of certain voltage-gated $\mathrm{K}^{+}$ channels, specifically, Kv1.4 and Kv3.4 (in which the "ball domain" is located in the $\mathrm{N}$ terminus of the $\alpha$ pore-forming subunit) and Kv1.1 co-expressed with the "ball domain"-containing $\mathrm{Kv} \beta 1.1$ accessory subunit (Oliver et al., 2004). Application of exogenous $\mathrm{PIP}_{2}$ to the intracellular side of the membrane expressing these channels removed the rapid $\mathrm{N}$-type inactivation, regardless of whether the "ball domain" resided at the $\mathrm{N}$ terminus of the channel $\alpha$ or $\beta$ subunit. It was proposed that $\mathrm{PIP}_{2}$ insertion into the plasma membrane immobilized the positively charged "ball domain" through its negatively charged head-group and thereby prevented it from accessing the open pore. In this study a cluster of positive residues formed by $\mathrm{Arg}^{13}$ and $\mathrm{Lys}^{14}$ in the "ball domain" of Kv3.4 were proposed as the place where the electrostatic interaction between the $\mathrm{PIP}_{2}$ and "ball domain" occurs (Oliver et al., 2004). Later, these findings were repeated for Kv1.5 channels coexpressed with the Kv $\beta 1.3$ accessory subunit. $\mathrm{PIP}_{2}$ eliminated the $\mathrm{Kv} \beta 1.3$ induced inactivation of Kv1.5 channels by immobilization of its "ball domain" as reported previously. An Arginine residue $\left(\mathrm{Agr}^{5}\right)$ in the $\mathrm{N}$ terminus of $\mathrm{Kv} \beta 1.3$ subunit was identified as a critical residue for $\mathrm{PIP}_{2}$ binding to the channel (Decher et al., 2008). Thus, changes in intracellular $\mathrm{PIP}_{2}$ levels might be important for the inactivation of $\mathrm{Kv}$ channels and this would profoundly alter electrical signaling.

Shab channels, a prototypical member of the Kv2 channels subfamily (Wei et al., 1990) are also modulated by PIP 2 . It was shown that standard light stimulation of Drosophila photoreceptors increased Shab currents (Krause et al., 2008). After light stimulation, the voltage dependence of activation of Shab channels was shifted to hyperpolarized potentials about $10 \mathrm{mV}$, with a small decrease on the current amplitude at depolarized potentials. The mechanism proposed for this modulation of Shab channels involves the activation of PLC $\beta 4$ and the resulting hydrolysis of
$\mathrm{PIP}_{2}$. Interestingly, a point mutation (R435Q) in the $\mathrm{N}$ terminus of the Shab channel abolished the $\mathrm{PIP}_{2}$ hydrolysis effect. The same results were obtained expressing recombinant Shab channels in Drosophila S2 cells and recording currents in inside-out patches. Within a few minutes of patch excision the threshold for activation was left-shifted about $10 \mathrm{mV}$, an effect that was almost completely reversed by application of diC8-PIP 2 to the patch. These results led Krause et al. (2008) to suggest that $\mathrm{PIP}_{2}$ may interact directly with the Shab channel and modulate its activity.

$\mathrm{Kv} 1.3$ is another voltage-gated $\mathrm{K}^{+}$channel reported to be modulated by $\mathrm{PIP}_{2}$. The Kv1.3 channel is important in the activation and function of effector memory T cells (Gilhar et al., 2011). Recently, it was reported that $\mathrm{PIP}_{2}$ applied through patch pipettes in whole-cell recordings significantly reduced Kv1.3 currents in Jurkat $\mathrm{T}$ cells and this regulation may be significant for the maintenance of $\mathrm{T}$ lymphocyte activation in immune responses (Matsushita et al., 2009). However, the mechanisms of this modulation need to be further explored.

Contrary to previous reports on $\mathrm{Kv}$ channel modulation by $\mathrm{PIP}_{2}$, Kruse et al. (2012) recently tested a long list of Kv channels and found most of them insensitive to $\mathrm{PIP}_{2}$; this list includes $\mathrm{Kv} 1.1 / \mathrm{Kv} \beta 1.1, \mathrm{Kv} 1.3, \mathrm{Kv} 1.4, \mathrm{Kv} 1.5 / \mathrm{Kv} \beta 1.3, \mathrm{Kv} 2.1, \mathrm{Kv} 3.4, \mathrm{Kv} 4.2$, and $\mathrm{Kv} 4.3$ (with different KChIPs). To test the effect of $\mathrm{PIP}_{2}$ on Kv channels this group used three different strategies to deplete $\mathrm{PIP}_{2}$ in intact cells, activation of the $G$ protein-coupled muscarinic receptor M1, a zebrafish voltage-sensitive lipid 5-phosphatase (Dr-VSP), or an engineered fusion protein carrying both lipid 4-phosphatase and 5-phosphatase activity (pseudojanin). Kruse and colleagues offer some explanations for the discrepancy between previous experiments and their results, principally relying on the different strategies used to modulate the $\mathrm{PIP}_{2}$ concentrations in the membrane. While previous groups applied exogenous $\mathrm{PIP}_{2}$ to inside-out excised patches risking to increase $\mathrm{PIP}_{2}$ concentration to supramaximal levels, this group transiently depleted $\mathrm{PIP}_{2}$ in the membrane of intact cells maintaining all the constituents of the cell near normal conditions (Hilgemann, 2012; Kruse et al., 2012).

Recently, we also examined the effects of $\mathrm{PIP}_{2}$ depletion on the voltage-dependent Kv1.2 channel using different approaches not only in inside-out patches but also in intact cells, using the voltagesensitive phosphatase Ci-VSP. We obtained similar results to the Cav channels, namely a bidirectional regulation, where $\mathrm{PIP}_{2}$ depletion left-shifted the voltage dependence of activation, increasing current at the same time it decreased the open probability causing an overall decrease in the current level (Figure 1C; RodriguezMenchaca et al., 2012). These two effects were kinetically distinct and exhibited distinct molecular determinants and sensitivities to $\mathrm{PIP}_{2}$. The effect on the voltage dependence of activation proceeded through interactions of the S4-S5 linker that links the voltage sensor to the channel pore with $\mathrm{PIP}_{2}$ (Figure 1A). Gating current measurements revealed that $\mathrm{PIP}_{2}$ constrains the movement of the sensor via specific interactions of basic residues with $\mathrm{PIP}_{2}$ in the closed state. In summary, using a similar strategy as Kruse et al. (2012) to transiently deplete PIP $_{2}$ in intact cells namely a voltagesensitive phosphatase, we obtained contrasting results showing a dual effect on Kv1.2 and Shaker channels after PIP $_{2}$ depletion. In contrast, Kruse et al. did not observe any effect on the current 


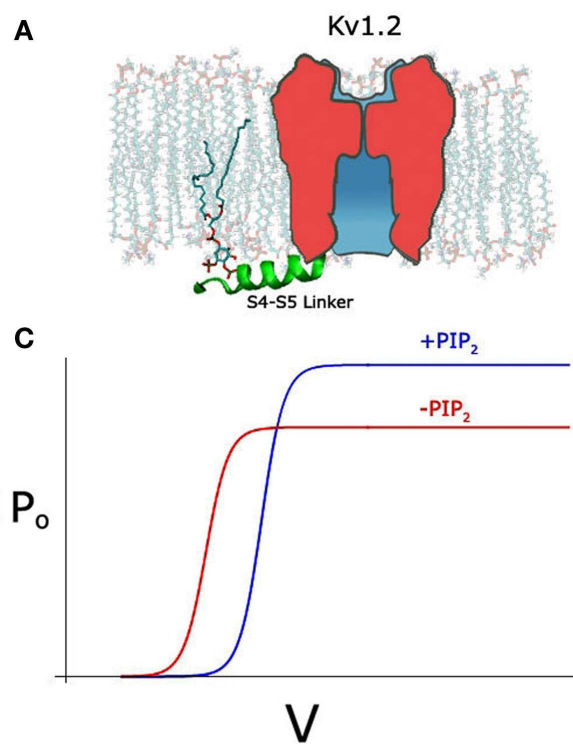

FIGURE 1 | (A) Schematic depicting $\mathrm{PIP}_{2}$ interacting with S4-S5 linker (green) in the Kv1.2 channel, with linker shown in cartoon representation. (B) Schematic depicting $\mathrm{PIP}_{2}$ interacting with $\mathrm{A}^{\prime}$ helix of C-linker (red) in the SplH channel, adapted from Flynn and Zagotta
B

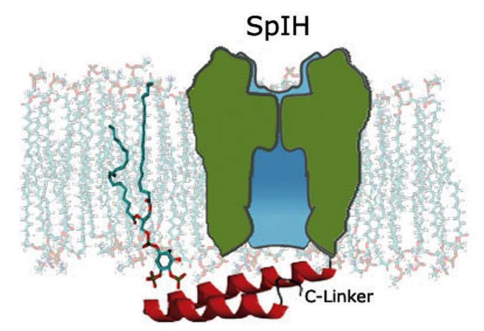

D

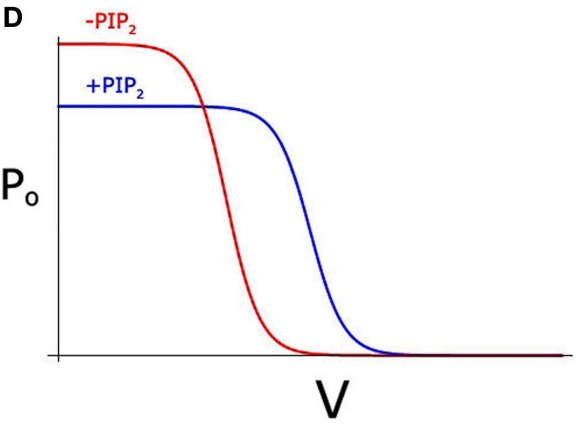

(2011). (C) Hypothetical Po-V curve of Kv1.2 showing depolarizing shift and increase in Po after PIP ${ }_{2}$ (blue line). (D) Hypothetical Po-V curve of SplH showing depolarizing shift and decrease in Po after $\mathrm{PIP}_{2}$ amplitude of several Kv channels after $\mathrm{PIP}_{2}$ depletion and did not test for changes in voltage dependency.

Consistent with our results, Abderemane-Ali et al. (2012) also reported a dual effect of $\mathrm{PIP}_{2}$ on Shaker potassium channels; $\mathrm{PIP}_{2}$ exerts a gain-of-function effect on the maximal current amplitude and a positive shift in the voltage dependence of activation, through an effect on the voltage sensor movement.

\section{HYPERPOLARIZATION-ACTIVATED HCN CHANNELS}

Hyperpolarization-activated Cyclic nucleotide-gated (HCN) channels unlike most voltage-gated channels open only in response to membrane hyperpolarization (Gauss et al., 1998; Ludwig et al., 1998; Santoro et al., 1998). The S1-S4 domain constitutes the voltage sensor again but with HCN channels the S4 segment moves inward upon membrane hyperpolarization (Mannikko et al., 2002; Bell et al., 2004). The coupling mechanism between this inward movement of the S4 and the opening of the gate, which is presumably located near the intracellular end of S6, is not clear. The cytoplasmic domain of HCN channels possesses a canonical cyclic nucleotide binding domain (CNBD). The CNBD is connected to the $\mathrm{S} 6$ segment through a 90-aa sequence called the C-linker (CL). Direct binding of cAMP or cGMP (cNMP) to the CNBD facilitates channel opening. At the macroscopic current level, the cNMPdependent gating right shifts the voltage dependence of activation and increases the current amplitude (Robinson and Siegelbaum, 2003; Craven and Zagotta, 2006; Biel et al., 2009). The CL plays a dominant role in the coupling of cNMP binding to the channel opening.

Hyperpolarization-activated cyclic nucleotide-gated channel activity is also under the control of $\mathrm{PIP}_{2}$. $\mathrm{PIP}_{2}$ right shifts the hyperpolarization-dependent $\mathrm{HCN}$ channel activation, making the channel easier to open (Pian et al., 2006; Zolles et al., 2006; Flynn and Zagotta, 2011; Ying et al., 2011). This effect is remarkable - about $20 \mathrm{mV}$ for mammalian HCN channels (HCN1, 2, and 4) and independent from the regulation by cAMP and cGMP. Direct evidence supporting these conclusions came from the experiments on inside-out membrane patches. Applying either native $\mathrm{PIP}_{2}$ or the soluble $\mathrm{diC}_{8}-\mathrm{PIP}_{2}$ produced a depolarizing shift in HCN channel activation (Pian et al., 2006; Zolles et al., 2006; Flynn and Zagotta, 2011). The right shift in the I-V relationship could be reproduced separately under conditions of saturating concentrations of cAMP, in mutant channels that do not bind to cNMP, or in the HCN $\triangle \mathrm{C}$ channels, in which the CL-CNBD has been deleted. Therefore, the interaction between $\mathrm{PIP}_{2}$ and the transmembrane domains with their connecting loops of $\mathrm{HCN}$ channels are likely to be responsible for the voltage-dependent effect rather than the CL and CNBD, which are essential for CAMPdependent gating. It has been suggested that most likely, $\mathrm{PIP}_{2}$ exerts its effect on voltage dependence by stabilizing the activated state of the voltage sensor, which could be through either a generalized effect on the local electrostatic environment by $\mathrm{PIP}_{2}$ or a specific interaction between the negatively charged head-group of $\mathrm{PIP}_{2}$ with positively charged residues in the $\mathrm{S} 4$ or its surroundings (Flynn and Zagotta, 2011).

SpIH, a HCN channel cloned from Sea Urchin, can be fully activated by cAMP but only partially by cGMP (Flynn et al., 2007). Unlike the mammalian HCN channels, SpIH shows a bidirectional regulation by $\mathrm{PIP}_{2}$ (Flynn and Zagotta, 2011). Like mammalian HCN channels it shows a right shift of the voltage dependence of activation $(\sim 10 \mathrm{mV})$ in the presence or $\mathrm{PIP}_{2}$, albeit half the magnitude of that in the mammalian channels (Figure 1D). Unlike the mammalian HCN channels, SpIH inactivates quickly in response 
to a hyperpolarizing voltage step (Gauss et al., 1998). Binding of cAMP or cGMP relieves this voltage-dependent inactivation and markedly increases the macroscopic current amplitude. Independent from the positive effect on the voltage-dependent activation, $\mathrm{PIP}_{2}$ seems to have an inhibitory effect on the cGMP-induced current (Figure 1D). This inhibitory effect is clearly related with the efficacy of the agonists. The maximal current under saturating concentration of CGMP is only about half of that of cAMP. Consistently, $\mathrm{PIP}_{2}$ strongly inhibits the cGMP-dependent current but has a minimal effect on the cAMP-induced current.

Noticeably, as reported more than a decade ago, $\mathrm{PIP}_{2}$ has a strong inhibitory effect on CNG channels, which is homologous to HCN channel and the cNMP binding is obligatory for its opening (Womack et al., 2000; Kaupp and Seifert, 2002). Several studies have produced atomic resolution structures of the HCN cytoplasmic C-terminal domains including that from SpIH channel (Zagotta et al., 2003; Flynn et al., 2007; Xu et al., 2010). Mutagenesis studies of the SpIH channel have identified several positively charged residues in the CL that contribute to the inhibitory effect by $\mathrm{PIP}_{2}$ (Figure 1B). It has been suggested that through these specific electrostatic interactions, $\mathrm{PIP}_{2}$ inhibits the channel opening by stabilizing the conformation of the CL that underlies the closed channel state in the absence of agonists (Flynn and Zagotta, 2011).

\section{CONCLUDING REMARKS}

The bidirectional effects of $\mathrm{PIP}_{2}$ in three very different voltage-sensitive channels is quite remarkable. In the

\section{REFERENCES}

Abderemane-Ali, F., Es-SalahLamoureux, Z., Delemotte, L., Kasimova, M. A., Labro, A. J., Snyders, D. J., Tarek, M., Baró, I., and Loussouarn, G. (2012). Dual effect of PIP2 on Shaker $\mathrm{K}^{+}$channels. J. Biol. Chem. doi: 10.1074/ jbc.M112.382085

Bell, D. C., Yao, H., Saenger, R. C., Riley, J. H., and Siegelbaum, S. A. (2004). Changes in local S4 environment provide a voltagesensing mechanism for mammalian hyperpolarization-activated $\mathrm{HCN}$ channels. J. Gen. Physiol. 123, 5-19.

Bernheim, L., Beech, D. J., and Hille, B. (1991). A diffusible second messenger mediates one of the pathways coupling receptors to calcium channels in rat sympathetic neurons. Neuron 6, 859-867.

Berridge, M. J. (1984). Inositol trisphosphate and diacylglycerol as second messengers. Biochem. J. 220, 345-360.

Bezanilla, F. (2008). How membrane proteins sense voltage. Nat. Rev. Mol. Cell Biol. 9, 323-332.

Biel, M., Wahl-Schott, C., Michalakis, S., and Zong, X. (2009). Hyperpolarization-activated cation channels: from genes to function. Physiol. Rev. 89, 847-885.
Borjesson, S. I., and Elinder, F. (2008). Structure, function, and modification of the voltage sensor in voltage-gated ion channels. Cell Biochem. Biophys. 52, 149-174.

Borjesson, S. I., Hammarström, S., and Elinder, F. (2008). Lipoelectric modification of ion channel voltage gating by polyunsaturated fatty acids. Biophys. J. 95, 2242-2253.

Brown, D. A., Abogadie, F. C., Allen, T. G., Buckley, N. J., Caulfield, M. P., Delmas, P., Haley, J. E., Lamas, J. A., and Selyanko, A. A. (1997). Muscarinic mechanisms in nerve cells. Life Sci. 60, 1137-1144.

Catterall, W. A. (2011). Voltage-gated calcium channels. Cold Spring Harb. Perspect. Biol. 3, a003947.

Catterall, W. A., Cestèle, S., YarovYarovoy, V., Yu, F. H., Konoki, K., and Scheuer, T. (2007). Voltage-gated ion channels and gating modifier toxins. Toxicon 49, 124-141.

Catterall, W. A., Perez-Reyes, E., Snutch, T. P., and Striessnig, J. (2005). International Union of Pharmacology. XLVIII. Nomenclature and structure-function relationships of voltage-gated calcium channels. Pharmacol. Rev. 57, 411-425.

Craven, K. B., and Zagotta, W. N. (2006). $\mathrm{CNG}$ and $\mathrm{HCN}$ channels: two peas, one pod. Annu. Rev. Physiol. 68, 375-401.

depolarization-activated Cav2.1 (Wu et al., 2002) and Kv1.2 (Rodriguez-Menchaca et al., 2012) studies, $\mathrm{PIP}_{2}$ right-shifted the voltage dependence of activation (inhibitory) while it prevented rundown by stabilizing the open probability of the channel (stimulatory). In the hyperpolarization-activated HCN channel from the sea urchin $(\mathrm{SpIH}) \mathrm{PIP}_{2}$ right-shifted the voltage dependence of activation (stimulatory), while it inhibited the cGMP-induced activation (inhibitory). In Kv1.2, $\mathrm{PIP}_{2}$ stabilized the inactive state of the voltage sensor by binding basic residues in the S4-S5 linker and the $\mathrm{N}$ terminus that could only coordinate $\mathrm{PIP}_{2}$ in the closed state of the channel. In the SpIH HCN channel it was CL basic residues that accounted for the non-voltage-dependent effects of $\mathrm{PIP}_{2}$. In both cases these molecular determinants affected only one or the other of the dual effects of $\mathrm{PIP}_{2}$. These results from these very different channels (Cav, Kv, and $\mathrm{HCN}$ ) suggest that the mechanism by which $\mathrm{PIP}_{2}$ regulates channels sensitive to voltage may be conserved.

What might be the physiological significance of the dual regulation of certain voltage-gated ion channels that we have highlighted in this review? We speculate that in channels that are dependent on voltage but also to other modulatory intracellular signals, a balance needs to be achieved to regulate gating in a coordinated manner. $\mathrm{PIP}_{2}$ and the $\mathrm{S} 4-\mathrm{S} 5$ linker are both perfectly positioned at the interface of the membrane to the cytosol to integrate cytosolic signals (e.g., cyclic nucleotides, $\mathrm{Ca}^{2+}$, etc.) with the movement of the transmembrane voltage sensor.

Davis, M. J., Wu, X., Nurkiewicz, T. R., Kawasaki, J., Gui, P., Hill, M. A., and Wilson, E. (2001). Regulation of ion channels by protein tyrosine phosphorylation. Am. J. Physiol. Heart Circ. Physiol. 281, 1835-1862.

Decher, N., Gonzalez, T., Streit, A. K. Sachse, F. B., Renigunta, V., Soom, M., Heinemann, S. H., Daut, J., and Sanguinetti, M. C. (2008). Structural determinants of Kvbetal.3induced channel inactivation: a hairpin modulated by PIP2. EMBO J. 27, 3164-3174.

Dolphin, A. C. (2003). G protein modulation of voltage-gated calcium channels. Pharmacol. Rev. 55 607-627.

Elinder, F., and Arhem, P. (2003). Metal ion effects on ion channel gating. $Q$. Rev. Biophys. 36, 373-427.

Flynn, G. E., Black, K. D., Islas, L. D., Sankaran, B., and Zagotta, W. N. (2007). Structure and rearrangements in the carboxy-terminal region of SpIH channels. Structure 15, 671-682.

Flynn, G. E., and Zagotta, W. N. (2011). Molecular mechanism underlying phosphatidylinositol 4,5-bisphosphate-induced inhibition of SpIH channels. J. Biol. Chem. 286, 15535-15542.

Fozzard, H. A., and Kyle, J. W. (2002). Do defects in ion channel glycosylation set the stage for lethal cardiac arrhythmias? Sci. STKE 130, pe19.

Gamper, N., Reznikov, V., Yamada, Y., Yang, J., and Shapiro, M. S. (2004). Phosphatidylinositol [correction] 4,5-bisphosphate signals underlie receptor-specific $\mathrm{Gq} / 11$ mediated modulation of $\mathrm{N}$-type $\mathrm{Ca}^{2+}$ channels. J. Neurosci. 24, 10980-10992.

Gauss, R., Seifert, R., and Kaupp, U. B. (1998). Molecular identification of a hyperpolarization-activated channel in sea urchin sperm. Nature 393, 583-587.

Gilhar, A., Bergman, R., Assay, B., Ullmann, Y., and Etzioni, A. (2011). The beneficial effect of blocking Kv1.3 in the psoriasiform SCID mouse model. J. Invest. Dermatol. 131, 118-124.

Gubitosi-Klug, R. A., Mancuso, D. J., and Gross, R. W. (2005). The human Kv1.1 channel is palmitoylated, modulating voltage sensing: identification of a palmitoylation consensus sequence. Proc. Natl. Acad. Sci. U.S.A. 102, 5964-5968.

Heneghan, J. F., Mitra-Ganguli, T., Stanish, L. F., Liu, L., Zhao, R., and Rittenhouse, A. R. (2009). The $\mathrm{Ca}^{2+}$ channel beta subunit determines whether stimulation of Gq-coupled receptors enhances or inhibit N current. J. Gen. Physiol. 134, 369-384. 
Herlitze, S., Garcia, D. E., Mackie, K., Hille, B., Scheuer, T., and Catterall, W. A. (1996). Modulation of $\mathrm{Ca}^{2+}$ channels by G-protein beta gamma subunits. Nature 380, 258-262.

Hilgemann, D. W. (2012). Fitting $\mathrm{Kv}$ potassium channels into the PIP2 puzzle: Hille group connects dots between illustrious HH groups. J. Gen. Physiol. 140, 245-248.

Hoshi, T., Zagotta, W. N., and Aldrich, R. W. (1991). Two types of inactivation in Shaker $\mathrm{K}^{+}$channels: effects of alterations in the carboxy-terminal region. Neuron 7, 547-556.

Ikeda, S. R. (1996). Voltage-dependent modulation of $\mathrm{N}$-type calcium channels by G-protein beta gamma subunits. Nature 380, 255-258.

Ikeda, S. R., and Dunlap, K. (1999). Voltage-dependent modulation of $\mathrm{N}$-type calcium channels: role of $\mathrm{G}$ protein subunits. Adv. Second Messenger Phosphoprotein Res. 33, 131-151.

Jindal, H. K., Folco, E. J., Liu, G. X., and Koren, G. (2008). Posttranslational modification of voltage-dependent potassium channel Kv1.5:COOHterminal palmitoylation modulates its biological properties. Am. J. Physiol. Heart Circ. Physiol. 294, 2012-2121.

Kaupp, U. B., and Seifert, R. (2002). Cyclic nucleotide-gated ion channels. Physiol. Rev. 82, 769-824.

Krause, Y., Krause, S., Huang, J., Liu, C. H., Hardie, R. C., and Weckström, M. (2008). Light-dependent modulation of Shab channels via phosphoinositide depletion in Drosophila photoreceptors. Neuron 59, 596-607.

Kruse, M., Hammond, G. R., and Hille, B. (2012). Regulation of voltage-gated potassium channels by PI(4,5)P2. J. Gen. Physiol. 140, 189-205.

Lechner, S. G., Hussl, S., Schicker, K. W., Drobny, H., and Boehm, S. (2005). Presynaptic inhibition via a phospholipase C- and phosphatidylinositol bisphosphate-dependent regulation of neuronal $\mathrm{Ca}^{2+}$ channels. Mol. Pharmacol. 68, 1387-1396.

Li, C. H., Zhang, Q., Teng, B., Mustafa, S. J., Huang, J. Y., and Yu, H. G. (2008). Src tyrosine kinase alters gating of hyperpolarization-activated HCN4 pacemaker channel through Tyr531. Am. J. Physiol. Cell Physiol. 294, 355-362.

Logothetis, D. E., Petrou, V. I., Adney, S. K., and Mahajan, R. (2010). Channelopathies linked to plasma membrane phosphoinositides. Pflugers Arch. 460, 321-341.
Long, S. B., Campbell, E. B., and Mackinnon, R. (2005). Voltage sensor of Kv1.2: structural basis of electromechanical coupling. Science 309, 903-908.

Ludwig, A., Zong, X., Jeglitsch, M., Hofmann, F., and Biel, M. (1998). A family of hyperpolarization-activated mammalian cation channels. Nature 393, 587-591.

Mannikko, R., Elinder, F., and Larsson, H. P. (2002). Voltage-sensing mechanism is conserved among ion channels gated by opposite voltages. Nature 419, 837-841.

Matsushita, Y., Ohya, S., Suzuki, Y., Itoda, H., Kimura, T., Yamamura, H. and Imaizumi, Y. (2009). Inhibition of Kv1.3 potassium current by phosphoinositides and stromal-derived factor-1alpha in Jurkat T cells. Am. J. Physiol. Cell Physiol. 296, 1079-1085.

Mitra-Ganguli, T., Vitko, I., Perez-Reyes, E., and Rittenhouse, A. R. (2009). Orientation of palmitoylated $\mathrm{CaV}$ beta2a relative to CaV2.2 is critical for slow pathway modulation of N. type $\mathrm{Ca}^{2+}$ current by tachykinin receptor activation. J. Gen. Physiol. 134, 385-396.

Mohapatra, D. P., Park, K. S., and Trimmer, J.S. (2007). Dynamic regulation of the voltage-gated Kv2.1 potassium channel by multisite phosphorylation. Biochem. Soc. Trans. 35, 1064-1068.

Mohapatra, D. P., and Trimmer, J. S. (2006). The Kv2.1 C terminus can autonomously transfer Kv2.1-like phosphorylation-dependent localization, voltage-dependent gating, and muscarinic modulation to diverse Kv channels. J. Neurosci. 26, 685-695.

Oliver, D., Lien, C. C., Soom, M., Baukrowitz, T., Jonas, P., and Fakler, B. (2004). Functional conversion between A-type and delayed rectifier $\mathrm{K}^{+}$channels by membrane lipids. Science 304, 265-270.

Perez-Burgos, A., Prieto, G. A., Galarraga, E., and Bargas, J. (2010). CaV2.1 channels are modulated by muscarinic M1 receptors through phosphoinositide hydrolysis in neostriatal neurons. Neuroscience 165, 293-299.

Pian, P., Bucchi, A., Robinson, R. B., and Siegelbaum, S. A. (2006). Regulation of gating and rundown of HCN hyperpolarization-activated channels by exogenous and endogenous PIP2. J. Gen. Physiol. 128, 593-604.

Ramu, Y., Xu, Y., and Lu, Z. (2006). Enzymatic activation of voltagegated potassium channels. Nature 442, 696-699.
Roberts-Crowley, M. L., Mitra-Ganduli, T., Liu, L., and Rittenhouse, A. R. (2009). Regulation of voltage-gated $\mathrm{Ca}^{2+}$ channels by lipids. Cell Calcium 45, 589-601.

Robinson, R. B., and Siegelbaum, S. A. (2003). Hyperpolarization-activated cation currents: from molecules to physiological function. Annu. Rev. Physiol. 65, 453-480.

Rodriguez-Menchaca, A. A., Adney, S. K., Tang, Q. Y., Meng, X. Y., Rosenhouse-Dantsker, A., Cui, M., and Logothetis, D. E. (2012). PIP2 controls voltage sensor movement and pore opening of $\mathrm{Kv}$ channels through the S4-S5 linker. Proc. Natl. Acad. Sci. U.S.A. 109, E2399-E2408.

Rousset, M., Cens, T., Gouin-Charnet, A., Scamps, F., and Charnet, P. (2004). $\mathrm{Ca}^{2+}$ and phosphatidylinositol 4,5-bisphosphate stabilize a Gbeta gamma-sensitive state of $\mathrm{Ca}$ V2 $\mathrm{Ca}^{2+}$ channels. J. Biol. Chem. 279, 14619-14630.

Santoro, B., Liu, D. T., Bartsch, D., Kandel, E. R., Siegelbaum, S. A., and Tibbs, G. R. (1998). Identification of a gene encoding a hyperpolarization-activated pacemaker channel of brain. Cell 93, 717-729.

Schmidt, D., Jiang, Q. X., and MacKinnon, R. (2006). Phospholipids and the origin of cationic gating charges in voltage sensors. Nature $444,775-779$.

Suh, B. C., and Hille, B. (2005). Regulation of ion channels by phosphatidylinositol 4,5-bisphosphate. Curr. Opin. Neurobiol. 15, 370-378.

Suh, B. C., and Hille, B. (2008). PIP2 is a necessary cofactor for ion channel function: how and why? Annu. Rev. Biophys. 37, 175-195.

Suh, B. C., Kim, D. I., Falkenburger, B. H., and Hille, B. (2012). Membrane-localized $\beta$-subunits alter the PIP2 regulation of highvoltage activated $\mathrm{Ca}^{2+}$ channels. Proc. Natl. Acad. Sci. U.S.A. 109, 3161-3166.

Suh, B. C., Leal, K., and Hille, B. (2010). Modulation of highvoltage activated $\mathrm{Ca}^{2+}$ channels by membrane phosphatidylinositol 4,5-bisphosphate. Neuron 67, 224-238.

Swartz, K. J. (2007). Tarantula toxins interacting with voltage sensors in potassium channels. Toxicon 49 213-230.

Watanabe, I., Wang, H. G., Sutachan, J. J., Zhu, J., Recio-Pinto, E., and Thornhill, W. B. (2003). Glycosylation affects rat Kv1.1 potassium channel gating by a combined surface potential and cooperative subunit interaction mechanism. J. Physiol. 550, 51-66.

Watanabe, I., Zhu, J., Sutachan, J. J., Gottschalk, A., Recio-Pinto, E., and Thornhill, W. B. (2007). The glycosylation state of Kv1.2 potassium channels affects trafficking, gating, and simulated action potentials. Brain Res. 1144, 1-18.

Wei, A., Covarrubias, M., Butler, A., Baker, K., Pak, M., and Salkoff, L. (1990). $\mathrm{K}^{+}$current diversity is produced by an extended gene family conserved in Drosophila and mouse. Science 248, 599-603.

Womack, K. B., Gordon, S. E., He, F., Wensel, T. G., Lu, C. C., and Hilgemann, D. W. (2000). Do phosphatidylinositides modulate vertebrate phototransduction? J. Neurosci. 20, 2792-2799.

Wu, L., Bauer, C. S., Zhen, X. G., Xie, C., and Yang, J. (2002). Dual regulation of voltage-gated calcium channels by PtdIns(4,5)P2. Nature 419, 947-952.

Xiao, Y. F., Sigg, D. C., and Leaf, A. (2005). The antiarrhythmic effect of $n-3$ polyunsaturated fatty acids: modulation of cardiac ion channels as a potential mechanism. J. Membr. Biol. 206, 141-154.

Xu, X., Vysotskaya, Z. V., Liu, Q., and Zhou, L. (2010). Structural basis for the cAMP-dependent gating in the human HCN4 channel. J. Biol. Chem. 285, 37082-37091.

Xu, X. P., Erichsen, D., Börjesson, S. I., Dahlin, M., Amark, P., and Elinder, F. (2008a). Polyunsaturated fatty acids and cerebrospinal fluid from children on the ketogenic diet open a voltage-gated $\mathrm{K}$ channel: a putative mechanism of antiseizure action. Epilepsy Res. 80, 57-66.

Xu, Y., Ramu, Y., and Lu, Z. (2008b). Removal of phospho-head groups of membrane lipids immobilizes voltage sensors of $\mathrm{K}^{+}$channels. Nature 451, 826-829.

Yellen, G. (1998). The moving parts of voltage-gated ion channels. Q. Rev. Biophys. 31, 239-295.

Yellen, G. (2002). The voltage-gated potassium channels and their relatives. Nature 419, 35-42.

Ying, S. W., Tibbs, G. R., Picollo, A., Abbas, S. Y., Sanford, R. R., Accardi, A., Hofmann, F., Ludwig, A., and Goldstein, P. A. (2011) PIP2-mediated HCN3 channel gating is crucial for rhythmic burst firing in thalamic intergeniculate leaflet neurons. J. Neurosci. 31, 10412-10423.

Zagotta, W. N., Olivier, N. B., Black, K. D., Young, E. C., Olson, R., and Gouaux, E. (2003). Structural basis 
for modulation and agonist specificity of HCN pacemaker channels. Nature 425, 200-205.

Zolles, G., Klocker, N., Wenzel, D., Weisser-Thomas, J., Fleischmann, B. K., Roeper, J., and Fakler, B. (2006). Pacemaking by HCN channels requires interaction with phosphoinositides. Neuron 52, 1027-1036.
Conflict of Interest Statement: The authors declare that the research was conducted in the absence of any commercial or financial relationships that could be construed as a potential conflict of interest.

Received: 12 May 2012; accepted: 04 September 2012; published online: 25 September 2012.
Citation: Rodríguez-Menchaca $A A$, Adney SK, Zhou $L$ and Logothetis DE (2012) Dual regulation of voltage-sensitive ion channels by $P_{2} P_{2}$. Front. Pharmacol. 3:170. doi: 10.3389/fphar.2012.00170

This article was submitted to Frontiers in Pharmacology of Ion Channels and Channelopathies, a specialty of Frontiers in Pharmacology.
Copyright (C) 2012 Rodríguez-Menchaca, Adney, Zhou and Logothetis. This is an open-access article distributed under the terms of the Creative Commons Attribution License, which permits use, distribution and reproduction in other forums, provided the original authors and source are credited and subject to any copyright notices concerning any third-party graphics etc. 